\title{
Getting Rid of the Horizontal-to-Vertical Strategy: A Case Report of a Japanese Research Psychologist
}

\author{
Kazuo Mori \\ Department of Educational Psychology, Tokyo University of Agriculture and Technology, Tokyo, Japan \\ Email: kaz-mori@cc.tuat.ac.jp
}

Received 7 March 2014; revised 9 April 2014; accepted 16 April 2014

Copyright (C 2014 by author and Scientific Research Publishing Inc. This work is licensed under the Creative Commons Attribution International License (CC BY). http://creativecommons.org/licenses/by/4.0/ (c) (i) Open Access

\begin{abstract}
Most Japanese research psychologists have used "Horizontal-to-Vertical Conversion Strategy" for their research, simply replicating experimental studies published in Western journals with Japanese participants and publishing papers only in Japanese (the traditional orthography of the Japanese language is vertical). This short article criticized this prevailing research strategy among Japanese psychologists and reported a series of studies resulted from an invention of new experimental procedure. It showed an example of a Japanese researcher who had got rid of the inadequate approach by inventing a new experimental method. It also aimed to encourage Japanese psychologists to conduct innovative research and publish their studies in English journals.
\end{abstract}

\section{Keywords}

Japanese Social Scientists; Research Strategies; Psychology; The MORI Technique

\section{The Horizontal-to-Vertical Strategy Used by Japanese Research Psychologists}

One of the popular strategies for Japanese research psychologists has been to replicate experimental studies published in Western journals with Japanese participants. Then, they write papers in Japanese and publish them in Japanese journals. Because the traditional orthography of the Japanese language is vertical, it was dubbed "Horizontal-to-Vertical Conversion Strategy.” There are over 10,000 Japanese research psychologists at more than 700 universities in Japan. The number of attendants at the recent International Congress of Psychology at Cape Town, South Africa in 2012, rose well over 800. Despite these not-negligible numbers, their presence among Western world of psychological research has been relatively modest. It seems resulted from the fact that most 
Japanese psychologists have conducted studies utilizing "Horizontal-to-Vertical Conversion Strategy.” They even seem to hide themselves by doing their research "secretly" and publishing only among them in Japanese. At the international conferences, they would choose poster sessions to present their works inconspicuously so that Western researchers would not notice them.

They have not been hiding themselves intentionally. They have difficulties in writing papers in English. Oral presentations at international conferences tend to be avoided because they are not proficient at speaking and listening in English, either. Of course, everybody knows the difficulty of learning foreign languages. However, the language barrier is much harder for Japanese researchers than the Westerners may imagine. Even those Japanese researchers who regularly publish papers in English need their manuscripts checked and edited by English native speakers, or by English editing services. I have been dependent on my American colleague myself to edit my English before submission.

In the late 1980s, one of my students wanted to conduct an eyewitness experiment using the post event distortion paradigm originated by Elizabeth F. Loftus [1]. It would be easier for us simply to replicate the Loftus study with Japanese participants. If we obtain similar results from the replication, it means the original findings are valid across two cultures. On the other hand, if there may be any difference found, it means we have found a cultural dependence of the phenomena. In either way, we can publish it in a Japanese journal. However, I despised the Horizontal-to-Vertical Strategy. We wanted to publish our study in a Western journal rather than in a local Japanese journal. Since we had difficulty in writing English, we needed another strategy.

\section{Invention of a New Experimental Procedure: The MORI Technique}

If we have a weak point, we need a strong point to cover it up. We tried to invent an innovative research method for eyewitness research in place of the Loftus method. In the Loftus method, the distorting information is provided after a participant witnessed an event. Meanwhile, in actual cases, there are groups of witnesses, and some of them may misperceive or oversee some details. Therefore, it often happens co-witnesses of the same event report differently what they observed. To investigate the co-witness interactions with different memory recollections, we need to present two different visual stimuli artificially to create discrepancies between co-witnesses' memory. In 3-D movies, two slightly different images are presented separately to the right and left eyes. There are several methods to accomplish this. One method is to use polarizing filters. A polarized light beam can pass through a polarizing filter with the same polarizing direction, while it cannot pass through a filter placed perpendicular to the polarizing direction. Then, if two different images are projected with differently polarized lights perpendicular each other, these two images can be observed separately through two polarizing filters. In

short, we invented a new presentation method with which the experimenters can present two different visual stimuli separately to two groups of viewers without being aware of the other stimuli (The MORI technique; [2]-[4]).

By utilizing the MORI technique, we reproduced in a laboratory the simulated situation with some discrepancies among co-witnesses' memory by letting them observe two slightly different versions of the same event without knowing so. Kanematsu, Mori, and Mori [5] found that witnesses tended to conform to their co-witnesses after having discussed among them. They rated high their confidence in their answers even when they answered what they actually observed but learned from their partners during the discussion. We also applied this method to witness conformity experiments by manipulating a variety of interpersonal variables of co-witnesses; male vs female [6], mother vs child [7], stranger vs lover [8] with high vs low visual acuity [9], and preschool child pairs [10].

The MORI technique provided a new research tool to a variety of psychological study areas other than witness memory research. Mori and Arai [11] presented the Asch line-judgment tasks to genuine participants of foursomes in the way that one of them would see the standard lines differently from the other three participants. We replicated the Asch findings without using confederates. We also applied the same experimental paradigm for examining conformity among six-year-old children [12]. Without using confederates, Mori and Mori [13] [14] also replicated the social comparison experiment [15]. Mori and Uchida [16] had junior high school pupils solve a series of anagram tasks. We secretly presented easy anagrams to some target pupils while they presented the others difficult ones. The target children having solved more anagrams than their classmates raised their self-efficacy. Surprisingly, their elevated self-efficacy lasted as long as a year. 


\section{A Concluding Remark}

The methodological innovation provided a Japanese researcher with language handicaps to publish several articles in English journals. At least I can get rid of the Horizontal-to-Vertical Strategy. It is rather ironical that one of my papers [17] was an example of the reverse application of the Horizontal-to-Vertical Strategy, because it was the first experimental replication of Kanematsu et al. [5] with Western participants.

\section{Acknowledgements}

I would like to express thanks to students in my laboratory for helping me improve the MORI technique as well as for conducting application experiments using it. My collaborators in New Zealand, Maryanne Garry and her students, contributed to development of the MORI technique. Special thanks are due to Lauren French, now Hewitt, who worked hardest during these years conducting the MORI experiments. I am also indebted to Rebecca Anne Marck for her superb work in editing the English manuscript.

\section{References}

[1] Loftus, E.F. (1975) Leading Question and the Eyewitness Report. Cognitive Psychology, 7, 560-572. http://dx.doi.org/10.1016/0010-0285(75)90023-7

[2] Mori, K. (2003) Surreptitiously Projecting Different Movies to Two Subsets of Viewers. Behavior Research Methods, Instruments, and Computers, 35, 599-604. http://dx.doi.org/10.3758/BF03195539

[3] Mori, K. (2007) A Revised Method for Projecting Two Different Movies to Two Groups of Viewers without Their Noticing the Duality. Behavior Research Methods, 39, 574-578. http://dx.doi.org/10.3758/BF03193028

[4] Mori, K. (2007) Projecting Two Words with One Machine: A Method for Presenting Two Different Visual Stimuli Using Just One Projector without Viewers’ Noticing the Duality. Behavior Research Methods, 39, 811-815.

http://dx.doi.org/10.3758/BF03192973

[5] Kanematsu, H., Mori, K. and Mori, H. (1996) Memory Distortion in Eyewitness Pairs Who Observed Nonconforming Events and Discussed Them. Cognitive Studies: Bulletin of the Japanese Cognitive Science Society, 3, 29-40.

[6] Hirokawa, K., Matsuno, E., Mori, K. and Ukita, J. (2006) Relationship between Masculinity-Femininity and Concession in an Experimental Collaborative Eyewitness Testimony. Asian Journal of Social Psychology, 9, 132-139. http://dx.doi.org/10.1111/j.1467-839X.2006.00190.x

[7] Mori, K. and Kitabayashi, M. (2009) How Child-Mother Pairs Reported What They Had Witnessed Together: An Experimental Examination Using the MORI Technique. Psychology Journal, 6, 60-69.

[8] French, L., Garry, M. and Mori, K. (2008) You Say Tomato? Collaborative Remembering Leads to More False Memories for Intimate Couples than for Strangers. Memory, 16, 262-273. http://dx.doi.org/10.1080/09658210701801491

[9] French, L., Garry, M. and Mori, K. (2011) Relative—Not Absolute_-Judgments of Credibility Affect Susceptibility to Misinformation Conveyed during Discussion. Acta Psychologica, 136, 119-128.

http://dx.doi.org/10.1016/j.actpsy.2010.10.009

[10] Mori, K. and Takahashi, R. (2012) Pre-Schoolers’ Reports of Conflicting Points Secretly Inserted into a Co-Witnessed Event: An Experimental Investigation Using the MORI Technique. Psychology, 3, 30-35. http://dx.doi.org/10.4236/psych.2012.31005

[11] Mori, K. and Arai, M. (2010) No Need to Fake It: Reproduction of the Asch Experiment without Using Confederates. International Journal of Psychology, 45, 390-397. http://dx.doi.org/10.1080/00207591003774485

[12] Hanayama, A. and Mori, K. (2011) Conformity of Six-Year-Old Children in the Asch Experiment without Using Confederates. Psychology, 2, 661-664. http://dx.doi.org/10.4236/psych.2011.27100

[13] Mori, K. and Mori, H. (2011) No Confederates Needed: Social Comparison without Collaboration. Social Behavior and Personality, 39, 543-552. http://dx.doi.org/10.2224/sbp.2011.39.4.543

[14] Mori, K. and Mori, H. (2013) Japanese Are Modest Even When They Are Winners: Competence Ratings of Self and Others in Social Comparison. Psychology, 4, 827-830. http://dx.doi.org/10.4236/psych.2013.411119

[15] Alicke, M.D., LoSchiavo, F.M., Zerbst, J. and Zhang, S. (1997) The Person Who Outperforms Me Is a Genius: Maintaining Perceived Competence in Upward Social Comparison. Journal of Personality and Social Psychology, 73, 781789. http://dx.doi.org/10.1037/0022-3514.73.4.781

[16] Mori, K. and Uchida, A. (2009) Can Contrived Success Affect Self-Efficacy among Junior High School Pupils? Re- 
search in Education, 82, 60-68. http://dx.doi.org/10.7227/RIE.82.5

[17] Garry, M., French, L., Kinzett, T. and Mori, K. (2008) Eyewitness Memory Following Discussion: Using the MORI Technique with a Western Sample. Applied Cognitive Psychology, 22, 431-439. http://dx.doi.org/10.1002/acp.1376 